\title{
The Canadian STOP-PAIN project - Part 2: What is the cost of pain for patients on waitlists of multidisciplinary pain treatment facilities?
}

\section{Le projet canadien STOP-PAIN - 2ème partie: Quel est le coût de la douleur pour les patients sur les listes d'attente des établissements pluridisciplinaires de traitement de la douleur?}

\author{
Denise N. Guerriere, $\mathrm{PhD} \cdot$ Manon Choinière, $\mathrm{PhD} \cdot$ Dominique Dion, MD • \\ Philip Peng, MBBS • Emma Stafford-Coyte, BSc • Brandon Zagorski, PhD • \\ Robert Banner, MD • Pamela M. Barton, MD • Aline Boulanger, MD • \\ Alexander J. Clark, MD • Allan S. Gordon, MD • Marie-Claude Guertin, PhD • \\ Howard M. Intrater, MD • Sandra M. Lefort, PhD • Mary E. Lynch, MD • \\ Dwight E. Moulin, MD • May Ong-Lam, MD • Mélanie Racine, PhD(c) • \\ Saifee Rashiq, MB · Yoram Shir, MD - Paul Taenzer, PhD · Mark Ware, MBBS
}

Received: 5 November 2009/Accepted: 15 March 2010/Published online: 23 April 2010

(C) Canadian Anesthesiologists' Society 2010

\begin{abstract}
Purpose The Canadian STOP-PAIN Project was designed to document the human and economic burden of chronic pain in individuals on waitlists of Multidisciplinary
\end{abstract}

This article is accompanied by an editorial. Please see Can J Anesth 2010; 57(6).

The economic analysis for the Canadian STOP-PAIN PROJECT was led by Denise N. Guerriere, Manon Choinière, Dominique Dion, Philip Peng, Emma Stafford-Coyte, and Brandon Zagorski. The other co-investigators were by alphabetical order: Robert Banner, Pamela M. Barton, Aline Boulanger, Alexander J. Clark, Allan S. Gordon, Marie-Claude Guertin, Howard M. Intrater, Sandra M. Lefort, Mary E. Lynch, Dwight E. Moulin, May Ong-Lam, Mélanie Racine, Saifee Rashiq, Yoram Shir, Paul Taenzer, Mark Ware.

Electronic supplementary material The online version of this article (doi:10.1007/s12630-010-9306-4) contains supplementary material, which is available to authorized users.

D. N. Guerriere, PhD $(\bowtie) \cdot$ E. Stafford-Coyte, BSc

Department of Health Policy, Management and Evaluation (HPME), Faculty of Medicine, University of Toronto, Health

Sciences Building, 155 College Street, 4th Floor, Toronto,

ON M5T 3M6, Canada

e-mail: denise.guerriere@utoronto.ca

M. Choinière, $\mathrm{PhD}$

Centre de recherche du Centre hospitalier de l'Université de

Montréal (CRCHUM), Québec, QC, Canada
Pain Treatment Facilities (MPTF). This paper describes the societal costs of their pain.

Methods A subgroup of 370 patients was selected randomly from The Canadian STOP-PAIN Project. Participants completed a self-administered costing tool (the Ambulatory and Home Care Record) on a daily basis for three months. They provided information about publicly financed resources, such as health care professional consultations and diagnostic tests as well as privately financed costs, including out-of-pocket expenditures and time devoted to seeking, receiving, and providing care. To determine the cost of care, resources were valued using various costing methods, and multivariate linear regression was used to predict total cost. Results Overall, the median monthly cost of care was $\$ 1,462$ (CDN) per study participant. Ninety-five percent of the total expenditures were privately financed. The final regression model consisted of the following determinants: educational level, employment status, province, pain

M. Choinière, $\mathrm{PhD}$ - M.-C. Guertin, $\mathrm{PhD}$

Montreal Heart Institute Coordinating Centre, Montréal, QC, Canada

D. Dion, MD

Department of Family Medicine, Faculty of Medicine,

University of Montreal, Montréal, QC, Canada 
duration, depression, and health-related quality of life. This model accounted for $35 \%$ of the variance in total expenditure $(P<0.001)$.

Conclusion The economic burden of chronic pain is substantial in patients on waitlists of MPTFs. Consequently, it is essential to consider this burden when making decisions regarding resource allocation and waitlist assignment for a MPTF. Resource allocation decision-making should include the economic implications of having patients wait for an assessment and for care.

\section{Résumé}

Objectif Le projet canadien STOP-PAIN a été élaboré afin de documenter le fardeau humain et économique que représentait la douleur chronique pour les personnes se trouvant sur les listes d'attente des établissements pluridisciplinaires de traitement de la douleur (MPTF Multidisciplinary Pain Treatment Facilities). Cet article décrit les coûts sociétaux de leur douleur.

Méthode Un sous-groupe de 370 patients a été aléatoirement choisi parmi les participants au projet canadien STOP-PAIN. Les participants ont rempli quotidiennement un outil auto-administré de calcul des coûts (le fichier de soins ambulatoires et à domicile - Ambulatory and Home Care Record) pendant trois mois. Ils ont fourni des renseignements concernant les ressources financées par le secteur public, comme par exemple les consultations auprès de professionnels de la santé et les tests diagnostiques, ainsi que les coûts privés, notamment les sorties effectives d'argent et le temps consacré à chercher, recevoir et fournir des soins. Afin de déterminer le coût des soins, les ressources ont été estimées à l'aide de plusieurs méthodes de calcul des coûts, et une analyse par

P. Peng, MBBS - A. S. Gordon, MD

Wasser Pain Management Clinic, Mount Sinai Hospital,

Toronto, ON, Canada

B. Zagorski, $\mathrm{PhD}$

Institute for Clinical Evaluative Sciences, Toronto, ON, Canada

R. Banner, MD · S. Rashiq, MB

Multidisciplinary Chronic Pain Centre, University of Alberta,

Edmonton, AB, Canada

P. M. Barton, MD · P. Taenzer, PhD

Chronic Pain Centre of the Calgary Health Region Centre,

Calgary, AB, Canada

A. Boulanger, MD

Pain Clinic of the Centre hospitalier de l'Université de Montréal, Montréal, QC, Canada

A. J. Clark, MD - M. E. Lynch, MD

Pain Management Unit, Queen Elizabeth II Health Sciences

Centre, Halifax, NS, Canada régression linéaire multivariée a été appliquée afin d'estimer le coût total.

Résultats Globalement, le coût mensuel moyen des soins était de $1462 \$(C D N)$ par participant à l'étude. Quatre-vingt-quinze pour cent des dépenses totales étaient prises en charge de façon privée. Le modèle de régression final était composé des déterminantes suivantes: niveau d'éducation, situation d'emploi, province, durée de la douleur, dépression, et qualité de vie par rapport à la santé. Ce modèle a justifié $35 \%$ de la variance des dépenses totales $(P<0,001)$.

Conclusion Le fardeau économique que représente la douleur chronique est substantiel pour les patients sur les listes d'attente des MPTF. Pour cette raison, il est nécessaire de tenir compte de ce fardeau lors de la prise de décision concernant l'attribution des ressources et l'affectation à la liste d'attente d'un MPTF. La prise de décision concernant l'attribution des ressources devrait inclure les implications économiques liées à l'attente des patients pour une évaluation de leur état et pour les soins.

Management of chronic pain is associated with increased use of health care resources. ${ }^{1-3}$ Since single modalities of treatment are rarely sufficient to treat chronic pain, patients seek out a myriad of both conventional and alternative treatments in a variety of health care settings. ${ }^{4,5}$ As not all of these services are publicly funded, the associated costs to manage the care of individuals with chronic pain are thought to be quite high. ${ }^{2}$ In addition, pain management may be time-consuming because of the time devoted to seeking and receiving care. Also, the physically debilitating effects of pain can interrupt daily activities, which

H. M. Intrater, MD

Health Sciences Centre Pain Clinic, University of Manitoba, Winnipeg, MB, Canada

S. M. Lefort, $\mathrm{PhD}$

School of Nursing, Memorial University of Newfoundland,

St John's, NL, Canada

D. E. Moulin, MD

London Health Sciences Centre, London, ON, Canada

M. Ong-Lam, MD

St-Paul's Hospital Pain Centre, Vancouver, BC, Canada

M. Racine, $\mathrm{PhD}(\mathrm{c})$

Department of Psychology, Université du Québec à Montréal,

Montréal, QC, Canada

Y. Shir, MD - M. Ware, MBBS

Pain Centre of the McGill University Health Centre, Montréal, QC, Canada 
results in sufferers and family members losing time from productive employment, leisure activities, and household work. Despite the belief that resource utilization by individuals with chronic pain is costly to both the health care system and to patients, very little is known about the economic burden of chronic pain.

Economic studies evaluating chronic pain have not provided a comprehensive and accurate measure of total health care costs, as most studies either address a subset of cost categories or consider only public or privately financed costs. ${ }^{4,6-9}$ Rates of health service utilization have been determined, ${ }^{6-8,10}$ but the economic consequences remain unknown because studies have reported rates rather than costs. In the studies that have reported public costs associated with chronic pain, ${ }^{8,11-14}$ some components of the costs were not included. None of the studies that measured time lost from employment captured the time that patients and family caregivers devoted to receiving and providing care and time they lost from leisure and household work..$^{11,12,14}$ As a result, these studies may have underestimated time costs.

Accordingly, the main purpose of this study was to use a comprehensive approach to measuring the societal costs of privately and publicly financing care for those patients with chronic pain who were referred to a Canadian Multidisciplinary Pain Treatment Facilities (MPTFs) and remained on the waitlist. Given that chronic pain places tremendous demands on patients and their family members, acquiring economic evidence is critical, particularly while waiting to be seen in a MPTF. Patients may be on these waitlists for many months or years, ${ }^{15,16}$ and little or no information exists about their specific needs and the economic burden of their pain. The secondary objective of this study was to assess the clinical and demographic determinants of the total costs of chronic pain in these patients. Understanding the magnitude and determinants of costs provides information on the extent to which the resources used by individuals with chronic pain vary according to the characteristics of the patients. Such information may identify an area where financial assistance is needed for patients and their families.

\section{Methods}

Recruitment and enrolment procedures of this study are reported in a companion paper in this issue of the Journal (see Choinière et al., The Canadian STOP-PAIN Project Part 1). A subgroup of 512 patients waiting to be treated in MPTFs was randomly selected from the larger study sample $(n=728)$ to complete the Ambulatory and Home Care Record (AHCR) ( $\odot$ Coyte \& Guerriere, 1998). ${ }^{17}$ To measure private and public expenditures, participants were asked to report their resource use by completing the AHCR on a daily basis over a three-month period. A research nurse conducted monthly telephone interviews with each patient to review the costs reported on the AHCR. This instrument has been used to assess ambulatory health care utilization for patients with both short-term and long-term health care needs, ${ }^{18-21}$ and it is currently being used in several studies within a variety of clinical care settings and with various populations. Evaluation of its psychometric properties has shown good to excellent agreement between participants' reports and administrative data (Kappa ranging from 0.41-1.00). ${ }^{17}$ For public expenditures, all services financed by the government were included: consultations with health care providers, laboratory and diagnostic tests, and medications covered by governmentsponsored drug programs. Private expenditures included out-of-pocket expenses incurred by patients and their family members, time costs, and third party insurance. Outof-pocket expenses included expenditures for consultations with health care professionals not covered by provincial health insurance, household help, medications, and travel expenses. Time costs refer to the monetary value assigned to the time patients and their family caregivers dedicated to receiving and providing care. Finally, third party insurance included payments insurance companies made for health care services.

The determinants of costs were examined using relevant information collected during the initial interview with the participants (refer to Choinière et al., The Canadian STOPPAIN Project - Part 1). The following variables were included in the analysis: cause of pain (trauma, surgery, illness, no precise event), pain duration, pain intensity during the past week (average, worst, and present pain on a 0-10 numerical rating scale [NRS] $)^{22}$ and its impact on daily living (interference items of the modified Brief Pain Inventory [BPI], ${ }^{23,24}$ depression levels (Beck Depression Inventory [BDI-I] $),{ }^{25}$ tendency to catastrophize in the face of pain (Pain Catastrophizing Scale [PCS] $),{ }^{26}$ health-related quality of life (QoL) (SF-36v2), ${ }^{27}$ and socio-demographics.

\section{Data analysis}

Resource utilization was valued using unit costs for the province of Ontario, and physician and laboratory costs were determined using the Ontario provincial fee-for-service rate schedule. The costs of clinic and emergency room visits were estimated using data from hospital or clinic cost accounting systems, and medication costs were derived using a government-sponsored drug benefit formulary rate. ${ }^{28}$ Although these unit costs may have been determined through regulatory and bargaining arrangements and may therefore represent an imperfect measure of "true" costs, 
these figures were used because they were readily available. All costs were reported in 2007 Canadian dollars.

For out-of-pocket expenses, the cost of travel by car was calculated using the cost per kilometre $(\$ 0.43 / \mathrm{km})$ as reported by the Canadian Automobile Association. The cost of all of the remaining out-of-pocket expenses was determined using the self-reported dollar value on the AHCR. The total out-of-pocket expense for each participant was calculated by summing the amounts reported and then subtracting any reimbursements received by the patient or the family from drug plans or medical insurance.

Time costs were determined by assigning a monetary value to each unit of time. Time lost from paid labour was valued in our study using the human capital approach. ${ }^{29,30}$ This approach applies current average earnings to lost time by age and gender. To value time lost from the labour market, age/sex based earnings estimates from the 2001 Census were adjusted for $15 \%$ nominal earnings growth to $2007,{ }^{\mathrm{A}}$ multiplied by 1.20 for employer paid benefits, ${ }^{31}$ and further multiplied by 52/46 to account for vacation days and holidays. Hourly rates ranged from $\$ 24.34$ to $\$ 34.63$ (2007 dollars). Time lost from unpaid labour/leisure time was valued using the estimated earnings of a homemaker from the 2001 Census and adjusted for earnings growth, fringe benefits, and vacation days and holidays. For each patient, the total time cost was computed as the product of the monetary value assigned to one unit of time and the total time lost to care-related activities.

All data were analyzed using SAS Version 9.1.3 (SAS Institute Inc., Cary, NC, USA). Three distributions of resource expenditures covering publicly financed, privately financed, and total care were computed to determine the cost of care. Appropriate measures of central tendency and dispersion were computed to describe the distributions.

Multivariate linear regression was used to investigate the relationship between pain predictors and total cost. Since total cost was positively skewed, log-transformed total cost (using log to the base 10) was the independent variable for the regression analysis. A limitation to this method is that the model is interpreted on a multiplicative scale, with the regression coefficients interpreted as the relative change in median cost with a one-unit increase in a predictor variable. ${ }^{32}$

We selected five pain variables: cause of pain, pain duration, pain intensity composite score (summation of the three NRS ratings), pain impact on daily living (summation of the BPI interference items), and tendency to catastrophize in the face of pain (PCS global score). Since these variables were likely to be collinear, they were tested in five separate regression models. Each model contained a reduced model of socio-demographic variables that were chosen, in part, on

\footnotetext{
A Annual Earnings Data. The Economist 2007; 27(October): 361.
}

the Andersen and Newman framework, ${ }^{33}$ which identifies factors influencing resource utilization. These variables included: age, gender, marital status, education level, employment status, household income, province, healthrelated QoL (SF-36v2 physical summary measure), and BDI-I score (depression). The SF36v2 mental domain was not included due to its collinearity with the BDI-I score. $\mathrm{R}$-squared was used to assess model fit, and the significance of each pain predictor was tested using the partial F-test. Error residuals were examined graphically using jackknife residuals. $^{34}$

\section{Results}

Three hundred and seventy of the selected participants (370/ 512: $72.3 \%$ ) completed the AHCR for at least one month. Others did not return the AHCR (125/512: 24.4\%) or were excluded because they attended their first appointment at the MPTF (17/512: 3.3\%). Two hundred and seventy-two participants completed the AHCR for three months, 35 for two months, and 63 for one month. Table 1 presents the demographic characteristics of the study participants. More than $60 \%$ of the participants were married (data not shown), and $36.8 \%$ were unable to work due to illness or disability. Pain duration varied from 0.5 to $55 \mathrm{yr}$ (median: $5.0 \mathrm{yr}$ ) (data not shown). Pain was unrelated to a specific event in $40.0 \%$ of the subjects; it was related to an accident in $37.0 \%$, an illness in $12.7 \%$, and surgery in $10.3 \%$ (data not shown).

Table 1 Demographic characteristics of the study participants $(n=370)$

\begin{tabular}{|c|c|c|c|}
\hline \multicolumn{4}{|l|}{ Characteristics } \\
\hline \multirow[t]{2}{*}{ Age } & \multirow[t]{2}{*}{$\begin{array}{l}\text { Mean } \pm \text { SD (range): } \\
\quad 49.4 \pm 12.8 \text { yr (20-87) }\end{array}$} & & \\
\hline & & $\%$ & $n$ \\
\hline Gender & Female & 62.9 & 233 \\
\hline \multirow{3}{*}{$\begin{array}{l}\text { Education } \\
\text { level }\end{array}$} & Elementary school, high school & 46.0 & 170 \\
\hline & College-technical school & 35.1 & 131 \\
\hline & University & 19.3 & 69 \\
\hline \multirow{5}{*}{$\begin{array}{l}\text { Employment } \\
\text { status }\end{array}$} & Employed in labour market & 29.7 & 110 \\
\hline & Homemakers & 10.3 & 38 \\
\hline & Retired & 14.3 & 53 \\
\hline & $\begin{array}{l}\text { Unable to work due to illness } \\
\text { or disability }\end{array}$ & 36.8 & 136 \\
\hline & Students/otherwise not employed & 8.9 & 33 \\
\hline \multirow{4}{*}{$\begin{array}{l}\text { Household } \\
\text { income }\end{array}$} & $\$ 15,000$ or less & 23.4 & 78 \\
\hline & $\$ 15,001-30,000$ & 20.4 & 67 \\
\hline & $\$ 30,001-60,000$ & 31.7 & 104 \\
\hline & $\$ 60,001$ or more & 24.1 & 79 \\
\hline
\end{tabular}

$\mathrm{SD}=$ standard deviation 
Table 2 Frequency of publicly and privately financed appointments per month for all participants over the data collection period

\begin{tabular}{lc}
\hline Appointment category & $\begin{array}{l}\text { Total number of } \\
\text { visits per month }\end{array}$ \\
\hline PUBLIC & 88 \\
Family physician & 46 \\
Physician specialist & 22 \\
Laboratory and diagnostic tests & 4 \\
Hospital visit & 4 \\
Physiotherapist & 3 \\
Clinic & 2 \\
Nurse & 1 \\
Counselor/psychologist & 5 \\
Other & \\
PRIVATE & 26 \\
Physiotherapist & 21 \\
Massage therapist & 13 \\
Family physician & 11 \\
Chiropractor & 11 \\
Counselor/psychologist & 10 \\
Physician specialist & 8 \\
Acupuncturist & 5 \\
Exercise consultant/trainer & 5 \\
Laboratory and diagnostic tests & 16 \\
Other &
\end{tabular}

\section{Categories of resource utilization}

Participants' reports of publicly- and privately-funded health care appointments were grouped into nine and ten categories, respectively (see Table 2). The frequencies represent the total number of visits for all participants irrespective of the number of months for which they provided data. Family physician visits were the most frequently reported (225 visits) of the publicly funded services. Physiotherapist and massage therapist appointments were the two most frequently reported privately-financed categories with 66 and 53 visits, respectively.

Costs of privately and publicly financed care

Table 3 presents the sum of monthly costs by expenditure category. Ninety-five percent of total expenditures were privately financed. The majority of time costs $(74 \%)$ were attributable to patients' lost time from work (55\%) and family caregivers' lost time from labour-market work (13\%). Most out-of-pocket expenditures were for medications and health care appointments; $35 \%$ and 24\%, respectively. Overall, the median monthly total cost of care for study participants was $\$ 1,462(\mathrm{CDN})($ mean $=\$ 3,112)($ Table 4$)$.
Table 3 Total monthly costs by expenditure category for all patients

\begin{tabular}{|c|c|c|}
\hline Expenditure category & Total Costs $\$$ & $\begin{array}{l}\% \text { of Overall } \\
\text { Total Costs }\end{array}$ \\
\hline \multicolumn{3}{|l|}{ PUBLIC } \\
\hline Health care appointments & 25,286 & $2.2 \%$ \\
\hline Hospitalization & 23,922 & $2.1 \%$ \\
\hline Medications & 8,190 & $0.7 \%$ \\
\hline Total public expenditures & 57,399 & $5.1 \%$ \\
\hline \multicolumn{3}{|l|}{ PRIVATE } \\
\hline \multicolumn{3}{|l|}{ A. Out-of-pocket } \\
\hline Healthcare appointments & 17,056 & $1.5 \%$ \\
\hline Medications & 25,767 & $2.3 \%$ \\
\hline Travel & 16,281 & $1.4 \%$ \\
\hline Paid household work & 13,386 & $1.2 \%$ \\
\hline Total out-of-pocket expenditures & 72,491 & $6.4 \%$ \\
\hline \multicolumn{3}{|l|}{ B. Private third party insurance } \\
\hline Healthcare appointments & 12,495 & $1.1 \%$ \\
\hline Medications/supplies & 33,298 & $2.9 \%$ \\
\hline Total third party insurance & 45,793 & $4.1 \%$ \\
\hline \multicolumn{3}{|l|}{ C. Time costs } \\
\hline \multicolumn{3}{|l|}{ Patient time loss from: } \\
\hline Labour-market & 585,074 & $51.8 \%$ \\
\hline Leisure & 71,651 & $6.4 \%$ \\
\hline \multicolumn{3}{|l|}{ Family caregiver time lost from: } \\
\hline Labour-market & 142,818 & $12.7 \%$ \\
\hline Leisure & 83,840 & $7.4 \%$ \\
\hline Household work & 69,735 & $6.2 \%$ \\
\hline Total time costs & 953,119 & $84.4 \%$ \\
\hline Total private costs $(A+B+C)$ & $1,071,403$ & $94.9 \%$ \\
\hline OVERALL TOTAL COSTS & $1,128,802$ & $100.0 \%$ \\
\hline
\end{tabular}

Determinants of total expenditures

For the multivariate analysis, the following variables did not make a statistically significant contribution to the regression cost model: age, gender, marital status, household income, cause of pain, pain impact on daily living, and tendency to catastrophize in the face of pain. The lack of statistical significance was not due to a limited range of variation on these variables. Consequently, the final regression model included the following determinants: educational level, employment status, province, pain duration, depression level, and health-related quality of life (see Table 5). This model accounted for $35 \%$ of the variance in total expenditure $(P<0.001)$. Classical assumptions for the regression model were met. $^{33}$

University education was significantly associated with higher expenditures devoted to chronic pain. Students and patients unable to work due to disability or illness tended to have higher overall costs than employed individuals and homemakers. Participants from Alberta had higher 
Table 4 Monthly costs per patient

\begin{tabular}{|c|c|c|c|c|c|}
\hline Expenditure category & Median & $\begin{array}{l}\text { Lower } \\
\text { quartile }\end{array}$ & $\begin{array}{l}\text { Upper } \\
\text { quartile }\end{array}$ & Mean & $\begin{array}{l}\text { Standard } \\
\text { deviation }\end{array}$ \\
\hline \multicolumn{6}{|l|}{ PUBLIC } \\
\hline Health care appointments & 40 & 0 & 85 & 68 & 141 \\
\hline Hospitalization & 0 & 0 & 0 & 65 & 407 \\
\hline Medications & 0 & 0 & 0 & 22 & 75 \\
\hline Total public expenditures & $\$ 43$ & $\$ 0$ & $\$ 109$ & $\$ 155$ & $\$ 478$ \\
\hline \multicolumn{6}{|l|}{ PRIVATE } \\
\hline \multicolumn{6}{|l|}{ A. Out-of-pocket } \\
\hline Health care appointments & 0 & 0 & 48 & 47 & 108 \\
\hline Medications & 23 & 6 & 68 & 71 & 171 \\
\hline Travel & 13 & 2 & 42 & 45 & 91 \\
\hline Paid household work & 0 & 0 & 30 & 37 & 89 \\
\hline Total out-of-pocket expenditures & 114 & 38 & 241 & 203 & 272 \\
\hline \multicolumn{6}{|l|}{ B. Private third party insurance } \\
\hline Health care appointments & 0 & 0 & 0 & 35 & 134 \\
\hline Medications/supplies & 8 & 0 & 119 & 92 & 165 \\
\hline Total third party insurance & 24 & 0 & 179 & 126 & 214 \\
\hline \multicolumn{6}{|l|}{ C. Time costs } \\
\hline \multicolumn{6}{|l|}{ Patient time lost from: } \\
\hline Labour market & 0 & 0 & 2,640 & 1,613 & 2,620 \\
\hline Leisure & 34 & 0 & 151 & 198 & 440 \\
\hline \multicolumn{6}{|l|}{ Family caregiver time lost from: } \\
\hline Labour market & 0 & 0 & 0 & 394 & 1,324 \\
\hline Leisure & 14 & 0 & 96 & 231 & 1,101 \\
\hline Household work & 0 & 0 & 155 & 192 & 530 \\
\hline Total time costs & 832 & 172 & 5,169 & 2,627 & 3,152 \\
\hline Total private costs $(A+B+C)$ & $\$ 1,280$ & $\$ 398$ & $\$ 5,489$ & $\$ 2,954$ & $\$ 3,218$ \\
\hline OVERALL TOTAL COSTS & $\$ 1,462$ & $\$ 460$ & $\$ 5,795$ & $\$ 3,112$ & $\$ 3,275$ \\
\hline
\end{tabular}

expenditures than Quebec participants, while participants from Ontario, British Columbia, Newfoundland and Labrador, and Nova Scotia had lower expenditures. Individuals with higher depression scores had higher expenditures than those who reported lower scores. Patients with lower quality of life scores on the physical component of the SF-36v2 had higher total costs. In contrast, participants with pain of longer duration tended to be associated with lower expenditures.

\section{Discussion}

In an environment of escalating medical costs, accurate and comprehensive data on the cost of health care utilization for chronic pain patients is crucial information for legislators in determining resource allocation. This Canadian study is designed to comprehensively and prospectively measure private and public costs associated with the management of chronic pain. The median and mean monthly costs of care for each study participant were $\$ 1,462$ and $\$ 3,112$, respectively. The majority of these costs were derived from patients' and family caregivers' time lost from labourmarket work. Educational attainment, work status, pain duration, depression levels, and health-related quality of life were statistically significant predictors of costs.

Time costs have received very little attention in the pain health care literature. In this study, patients' costs associated with time lost from labour-market employment were substantial. By valuing patients' and family caregivers' time in monetary terms, care receiving and caregiving can be compared or combined with out-of-pocket costs and public expenditures associated with chronic pain management. This methodological work is essential for future studies evaluating the cost-effectiveness of pain interventions and treatment programs.

Comparing our study results with other studies that focus on the costs of chronic pain is problematic for several 
Table 5 Determinants of total expenditures: multivariate linear regression model results
$\mathrm{CI}=$ confidence interval; $\mathrm{BDI}=$ Beck Depression Inventory

\begin{tabular}{|c|c|c|c|}
\hline Variables & $P$ value & $\begin{array}{l}\text { Multiplier } \\
\text { of outcome }\end{array}$ & $95 \% \mathrm{CI}$ \\
\hline \multicolumn{4}{|l|}{ Education level } \\
\hline university $v s \leq$ high school & 0.03 & 1.20 & $1.02-1.43$ \\
\hline \multicolumn{4}{|l|}{ Employment status } \\
\hline $\begin{array}{l}\text { unable to work due to illness or disability } \\
\text { vs employed/homemaker }\end{array}$ & $<0.0001$ & 1.71 & $1.45-2.01$ \\
\hline student/other $v s$ employed/homemaker & 0.02 & 1.34 & $1.05-1.71$ \\
\hline \multicolumn{4}{|l|}{ Province } \\
\hline Alberta $v s$ Quebec & 0.02 & 1.25 & $1.04-1.52$ \\
\hline British Columbia vs Quebec & 0.02 & 0.77 & $0.61-0.96$ \\
\hline Newfoundland and Labrador vs Quebec & 0.04 & 0.75 & $0.57-0.98$ \\
\hline Nova Scotia vs Quebec & $<0.0001$ & 0.70 & $0.58-0.85$ \\
\hline Ontario vs Quebec & $<0.0001$ & 0.68 & $0.56-0.83$ \\
\hline Pain duration (10 yr increase) & 0.05 & 0.93 & $0.87-1.00$ \\
\hline Depression level (BDI global score) (10 pt increase) & 0.05 & 1.08 & $1.00-1.16$ \\
\hline SF-36v2 Physical summary measure & $<0.0001$ & 0.44 & $0.29-0.67$ \\
\hline
\end{tabular}

reasons. Unlike our comprehensive approach that considered both sources of finance (private and public) and the various categories of expenditure, including time costs, other studies were not as all-inclusive in their methodology. In addition, comparisons with studies conducted outside of North America are limited due to differences in health care delivery and practice models. As a result, we compared three studies attentively and reviewed individual cost categories rather than total expenditures.

In our study, all categories of private expenditures were considered (out-of-pocket, time, and third party insurance) and measured comprehensively. To date, no studies have measured the time family caregivers or patients have lost from their leisure and household work; consequently, we compared our costs for patients' time lost from the labour market with two other studies. In a Swedish study, the mean annual cost of a patient's missed time from the labour market due to chronic lower back pain was 9,563 euros $(\$ 14,184 \mathrm{CDN}, 2002$ inflated to $\$ 15,815,2007) .^{8}$ For comparison, we annualized our mean cost to $\$ 19,356 \mathrm{CDN}$ $(\$ 1,613 \times 12)$. This cost difference may be related to different patient pain samples. The Swedish sample dealt with patients seeking care from primary care physicians, while our study embraced a diversified chronic pain population seeking care from a specialist in a MPTF. In all likelihood, our sample represented a more severely disabled group and, consequently, a higher proportion of time missed from work. Similar to our study, the Swedish study demonstrated that the majority of the costs were due to time losses. The findings suggest that more effective treatments for chronic pain could lead to cost savings despite higher costs for therapy. Compared with both the Swedish study and our study, mean costs were much lower in an American study, i.e., \$5,339 USD per year (\$7,918 CDN, 1998 inflated to $\$ 9,660,2007)$, that assessed time costs due to a patient's absence from employment due to lower back pain. ${ }^{14}$ However, it is not possible to account for the reported differences because the valuation process was not described.

In the Swedish study, which also measured public costs of pain, an average annual cost for visits with physicians, chiropractors, and physiotherapists was reported to be 1,681 euros $(\$ 2,493 \mathrm{CDN}, 2002$ inflated to $\$ 2,779.69,2007){ }^{8}$ This is in sharp contrast to our study in which the mean cost of publicly financed visits to health care professionals was $\$ 68$ per month or $\$ 816$ per year. Since appointments with physiotherapists and chiropractors are not included in our publicly financed category, they were based on out-of-pocket payments. If we combine publicly and privately financed health care appointments, the mean annual cost is $\$ 1,800$ per year. In Canada, the high proportion $(55 \%)$ of the cost of privately financed health care utilization may reflect the limited availability and accessibility of these services in the publicly funded system, in concert with chronic pain patients who are desperate to get well and possibly willing to pay for more accessible privately funded health care resources.

In a Danish study, the mean monthly cost for appointments with physicians, physiotherapists, chiropractors, psychologists, and diagnostic tests was 35 euros (\$48 CDN, 2000 inflated to $\$ 56,2007$ ) for individuals waiting to be seen in a multidisciplinary pain centre. ${ }^{13}$ While this cost is slightly lower than our figure, the Danish study included fewer services. Furthermore, the European studies did not indicate whether privately insured services were included, thereby making comparisons difficult. 
The mean monthly public and private expenditures for medications was \$22 and \$71, respectively, yielding a total monthly expenditure of $\$ 93$. Thomsen et al. ${ }^{13}$ reported a mean cost for medications of 63 euros $(\$ 86 \mathrm{CDN}, 2000$ dollars inflated to $\$ 101,2007)$ per month, and Ekman et al. reported a mean annual cost of medications of 183 euros (\$271 CDN, 2002 dollars inflated to $\$ 302,2008$ ). If annualized, our average annual costs for medications would be $\$ 1,116 \mathrm{CDN}$. However, comparison with the two European studies is problematic, because they did not specify if insurance payments for medications and complementary medications were included.

The regression model in this study explained $35 \%$ of the variance in total expenditures. In the Swedish study, $14 \%$ of the variance in total expenditures was explained by higher disease severity, longer duration of pain, and being female. ${ }^{8}$ This is contrary to our study, which found that patients with longer pain duration had lower costs than those who had experienced pain for a shorter period of time. However, our independent variable (total expenditures) is inconsistent with theirs for the reasons previously stated, i.e., in their study, not all components of time costs were included and they included only three types of professional visits. Also, it was not stated whether they included insurance payments. In addition, it is to be expected that patients with a longer duration of pain would have tried and paid out-of-pocket for many treatments (traditional and non-traditional) at the beginning of their pain experience, and, as time went on, their ongoing expenditure on new treatments would have decreased when these treatments were ineffective.

Our regression indicated that participants from Alberta had higher expenditures, while those from Ontario, British Columbia, Newfoundland and Labrador, and Nova Scotia had lower expenditures compared with the province of Quebec. Since we used the unit costs from Ontario to value the resources reported from each of the province study sites, the differences are attributed to utilization rates rather than unit cost differences.

As described above, it is challenging to compare our study with other economic pain studies, because our cost categories are more inclusive than those from previous studies. However, we are able to compare our results to two previous Canadian studies that used the same methodology but with a different diagnostic group. One study assessed the economic burden experienced by adults with cystic fibrosis who were in a stable clinical state, i.e., not experiencing an exacerbation. The total median monthly cost was $\$ 1,361$ (2002 CDN), which is almost equal to the median monthly cost in this current study $(\$ 1,491) .{ }^{19}$ In another study, the median monthly cost was much higher $(\$ 5,108)$. However, the patients in this study were receiving formal publicly funded home-based services. In addition, they had a variety of diagnoses, and they had low levels of physical functioning and high caregiving needs. ${ }^{20}$

There are limitations associated with our study that require comment. The results of this study cannot be generalized to other populations of patients with chronic pain, such as those seeking care from family physicians or those who are being treated at a MPTF or have already been treated. When patients are on a MPTF waitlist, it must be considered that their family physician may be less likely to arrange further investigations or additional specialist consultations. Should this be the case, this study's monthly costs may underestimate the cost for similar patients who are not on MPTFs waitlists. As mentioned earlier, it is also possible that patients on waitlists spend less money on new treatments because they have tried numerous ones in the past that were ineffective. Another limitation of the present study pertains to the AHCR data collection method that relied on self-reports and, therefore, errors may have been made during questionnaire completion. However, research nurses reviewed all completed questionnaires on a monthly basis and contacted each participant to clarify or complete any unclear or incomplete data. In addition, not all participants completed the AHCR at all three data collection time points. Deriving costs using one month of data collection may have resulted in an overestimation or underestimation of expenses, as resource utilization rates may have changed over the three-month time period. Finally, the accuracy of the methods used for deriving costs may be questioned, and the methods used for assigning a monetary value to time losses may be biased. For example, societal biases related to equity may place a higher monetary value on one unit of lost time for a male compared with the same unit of lost time for a female.

Despite these study limitations, it can be concluded that the economic burden of chronic pain is substantial in patients on MPTFs waitlists. Although it is not entirely known whether costs increase or decrease after patients are treated in a MPTF, there is some evidence indicating that costs decrease. ${ }^{35-38}$ Further research is required to explore private and public changes to cost over time so as to determine how all cost categories function following MPTF treatment. Given that chronic pain places tremendous demands on patients and their family members, it is critical to acquiring economic evidence. The various distributions of private and public expenditures have important implications for decision-making. Most of the burden of care was experienced by patients and their families rather than by the public sector. Furthermore, out-of-pocket expenditures were almost identical to those incurred by the public sector. Consequently, when decisions are made regarding resource allocation and assignment to a MPTF waitlist, it is essential to consider the significant burden borne by 
patients and their families. The economic implications of having people wait for an assessment and for care should be included in resource allocation decision-making. We emphasize the need to consider providing support to family caregivers, especially those who are forgoing time in the labour market to assist with caregiving. The economic implications of chronic pain on patients and family caregivers should be included in resource allocation, and families that are particularly vulnerable will require additional support.

Acknowledgements The authors sincerely thank Mrs. Hélène Lanctôt, Research Coordinator of the STOP-PAIN Project and the research nurses who were in charge of patient recruitment and data collection: Mary Beth Booker, Linda Ferguson, Donna Hefferton, Denise Héroux, Louise Malysh, Paulette Nauss, Lynda Oliveros, Mala Ramu, Teralyne Wilson, Joanne Smith-Yong, and Myrna Yazer.

Funding sources This study was funded by the Canadian Institutes of Health Research/Rx\&D Collaborative Research Program (Grant No. DOP 68175) in partnership with Pfizer Canada Inc. Additional funds were obtained from three research networks of Fonds de la recherche en santé du Québec (FRSQ): the Oral Health Research Network, the Neurosciences and Mental Health Research Network, and the Rehabilitation Research Network. Mélanie Racine is a Canadian Institutes of Health Research Strategic Training Fellow in «Pain Research: From Molecules to Community». Pfizer Canada Inc. did not influence the design, conduct, or reporting of the trial in any manner.

Competing interests None declared.

\section{References}

1. Eriksen J, Jensen MK, Sjogren P, Ekholm O, Rasmussen NK. Epidemiology of chronic non-malignant pain in Denmark. Pain 2003; 106: 221-8.

2. Loeser JD. Economic implications of pain management. Acta Anaesthesiol Scand 1999; 43: 957-9.

3. Turk DC. Chronic non-malignant pain patients and health economic consequences. Eur J Pain 2002; 6: 353-5.

4. Eisenberg DM, Davis RB, Ettner SL, et al. Trends in alternative medicine use in the United States, 1990-1997: results of a followup national survey. JAMA 1998; 280: 1569-75.

5. Kessler RC, Davis RB, Foster DF, et al. Long-term trends in the use of complementary and alternative medical therapies in the United States. Ann Intern Med 2001; 135: 262-8.

6. Blyth FM, March LM, Cousins MJ. Chronic pain-related disability and use of analgesia and health services in a Sydney community. Med J Aust 2003; 179: 84-7.

7. Blyth FM, March LM, Brnabic AJ, Cousins MJ. Chronic pain and frequent use of health care. Pain 2004; 111: 51-8.

8. Ekman M, Jonhagen S, Hunsche E, Jonsson L. Burden of illness of chronic low back pain in Sweden: a cross-sectional, retrospective study in primary care setting. Spine (Phila Pa 1976) 2005; 30: 1777-85.

9. Linton SJ, Hellsing AL, Hallden K. A population-based study of spinal pain among 35-45-year-old individuals. Prevalence, sick leave, and health care use. Spine (Phila Pa 1976) 1998; 23: 1457-63.
10. Eriksen J, Sjogren P, Ekholm O, Rasmussen NK. Health care utilisation among individuals reporting long-term pain: an epidemiological study based on Danish National Health Surveys. Eur J Pain 2004; 8: 517-23.

11. Sheehan J, McKay J, Ryan M, Walsh N, O'Keeffe D. What cost chronic pain? Ir Med J 1996; 89: 218-9.

12. Mantyselka PT, Kumpusalo EA, Ahonen RS, Takala JK. Direct and indirect costs of managing patients with musculoskeletal painchallenge for health care. Eur J Pain 2002; 6: 141-8.

13. Thomsen AB, Sorensen J, Sjogren P, Eriksen J. Chronic nonmalignant pain patients and health economic consequences. Eur $\mathrm{J}$ Pain 2002; 6: 341-52.

14. Pizzi LT, Carter CT, Howell JB, Vallow SM, Crawford AG, Frank $E D$. Work loss, healthcare utilization, and costs among US employees with chronic pain. Disease Management \& Health Outcomes 2005; 13: 201-8.

15. Veillette $Y$, Dion D, Altier N, Choiniere M. The treatment of chronic pain in Québec: a study of hospital-based services offered within anesthesia departments. Can J Anesth 2005; 52: 600-6.

16. Peng $P$, Choiniere $M$, Dion D, et al. Challenges in accessing multidisciplinary pain treatment facilities in Canada. Can J Anesth 2007; 54: 977-84.

17. Guerriere DN, Ungar WJ, Corey M, et al. Evaluation of the ambulatory and home care record: agreement between selfreports and administrative data. Int $\mathrm{J}$ Technol Assess Health Care 2006; 22: 203-10.

18. Stevens B, Guerriere D, McKeever P, et al. Economics of home vs. hospital breastfeeding support for newborns. J Adv Nurs 2006; 53: 233-43.

19. Guerriere DN, Tullis E, Ungar WJ, et al. Economic burden of ambulatory and home-based care for adults with cystic fibrosis. Treat Respir Med 2006; 5: 351-9.

20. Guerriere DN, Wong AY, Croxford R, Leong VW, McKeever P, Coyte PC. Costs and determinants of privately financed homebased health care in Ontario, Canada. Health Soc Care Community 2008 ; 16 : 126-36.

21. Leong VW, Guerriere DN, Croxford R, Coyte PC. The magnitude, share and determinants of private costs incurred by clients (and their caregivers) of in-home publicly financed care. Healthc Policy 2007; 3: e141-59.

22. Jensen $M K$, Karoly $P$. Self-report scales and procedures for assessing pain in adults. In: Turk DC, Melzack R (Eds). Handbook of pain assessment, 2nd ed. NY: Guilford Press ed.; 2001: 15-34.

23. Cleeland CS, Ryan KM. Pain assessment: global use of the Brief Pain Inventory. Ann Acad Med Singapore 1994; 23: 129-38.

24. Tyler EJ, Jensen MP, Engel JM, Schwartz L. The reliability and validity of pain interference measures in persons with cerebral palsy. Arch Phys Med Rehabil 2002; 83: 236-9.

25. Beck AT, Ward CH, Mendelson M, Mock J, Erbaugh J. An inventory for measuring depression. Arch Gen Psychiatry 1961; 4: 561-71.

26. Sullivan MJ, Bishop SR, Pivik J. The pain catastrophizing scale: development and validation. Psychol Assess 1995; 7: 524-32.

27. Ware JE Jr, Kosinski M, Dewey JE. How to Score Version 2 of the SF-36 Health Survey (Standard and Acute Forms). 2nd ed. Lincoln, RI: QualityMetric Incorporated - www.QualityMetric.com; 2001

28. Ontario Health Insurance Plan. Ministry of health and long-term Care 2004. Available from URL: http://www.health.gov.on.ca/en/ public/programs/ohip/ (accessed January 2010)

29. Rice DP, MacKenzie EJ. Cost of injury in the United States : a report to Congress. San Francisco, CA: The John Hopkins University; 1989.

30. Torgerson DJ, Donaldson C, Reid DM. Private versus social opportunity cost of time: valuing time in the demand for health care. Health Econ 1994; 3: 149-55. 
31. Chan B, Coyte P, Heick $C$. Economic impact of cardiovascular disease in Canada. Can J Cardiol 1996; 12: 1000-6.

32. Austin PC, Ghali WA, Tu JV. A comparison of several regression models for analysing cost of CABG surgery. Stat Med 2003; 22: 2799-815.

33. Andersen R, Newman JF. Societal and individual determinants of medical care utilization in the United States. Milbank Mem Fund Q Health Soc 1973; 51: 95-124.

34. Kleinbaum DG, Kupper LL, Muller KL, Nizam A. Applied Regression Analysis and Other Multivariables Methods. 3rd ed. Pacific Grove: Brooks/Cole Publishing Company; 1998.

35. McQuay HJ, Moore RA, Eccleston C, Morley S, Williams AC. Systematic review of outpatient services for chronic pain control. Health Technol Assess 1997; 1: i-135.
36. Weir R, Browne GB, Tunks E, Gafni A, Roberts J. A profile of users of specialty pain clinic services: predictors of use and cost estimates. J Clin Epidemiol 1992; 45: 1399-415.

37. Bondegaard TA, Sorensen J, Eriksen J. Economic evaluation of multidisciplinary pain management in chronic pain patients: a qualitative systematic review. J Pain Symptom Manage 2001; 22: 688-98.

38. Gatchel RJ, Okifuji A. Evidence-based scientific data documenting the treatment and cost-effectiveness of comprehensive pain programs for chronic nonmalignant pain. J Pain 2006; 7: 779-93. 